\title{
What does radiotherapy add to survival over endoscopic intubation alone in inoperable squamous cell oesophageal cancer?
}

\author{
S E Oliver, C S Robertson, R F A Logan, M Sokal, J C G Pearson, M Atkinson
}

\begin{abstract}
The place of radiotherapy in the management of squamous cell oesophageal cancer remains uncertain. Survival of oesophageal cancer patients from the Nottingham area in the years 1982-5 was reviewed. Surgical resection was attempted in 44 of 131 patients with squamous cell oesophageal cancer. Among the remainder 32 had endoscopic intubation alone, 27 had radical radiotherapy alone (six) or combined with endoscopic intubation (21), and 28 had other treatment combinations including surgical intubation and palliative radiotherapy. Patients treated by intubation alone had a mean age of 75 years. They were significantly older and metastases were more common $(31 \%)$ in this group than in patients treated with radiotherapy (mean age 69 years), of whom $11 \%$ had metastases. Some $34 \%$ (11 of 32 ) of patients treated by intubation alone died within 30 days of diagnosis and were therefore not eligible for radiotherapy. Beyond 30 days, survival in the radiotherapy group (median survival 188 days; $95 \%$ confidence limits $133-253$ ) was not significantly greater than that for the group treated by intubation alone (median survival 98 days (73-154)). The radiotherapy patients had a median hospital stay of $\mathbf{4 6}$ days compared with 23 days for the patients treated by intubation alone. In patients with squamous cell oesophageal cancer unsuitable for surgery, the survival advantage associated with radiotherapy and intubation is small and does not compensate for the extra morbidity and prolonged hospital stay. A controlled trial of radiotherapy in these patients is now needed.
\end{abstract}

University Departments of Community Medicine and Epidemiology and Surgery, University Hospital, Nottingham $S$ E Oliver C S Robertson

R F A Logan

J C G Pearson

M Atkinson

Department of Clinical Oncology, General Oncology, General
Hospital, Nottingham M Sokal

Correspondence to:

Dr R F A Logan, Department of Community Medicine and Epidemiology, University of Nottingham Medical School, Queen's Medical Centre

Nottingham NG7 2UH

Accepted for publication 5 October 1989
Cancer of the oesophagus causes about 4500 deaths each year in England and Wales.' Whatever the treatment, the results are generally disappointing and less than $8 \%$ of all patients survive five years. ${ }^{2}$ The place of radiotherapy in the management of squamous cell oesophageal cancer is unclear and its role as a first choice treatment has still to be subjected to controlled trial.

In Nottingham, patients considered suitable in terms of fitness and disease extent are generally offered surgery. Most remaining patients are treated either by endoscopic intubation alone or by radiotherapy (radical or palliative) with or without intubation. The question arises as to whether radiotherapy confers a survival advantage over intubation alone and, if so, whether this outweighs any increased morbidity or extended hospital stay.
Methods

New patients presenting to the Nottingham University and City Hospitals with oesophageal cancer in the four year period 1982-5 were retrospectively identified from three sources - (a) hospital activity analysis data, (b) histopathology records, and (c) endoscopy unit records. This search showed 496 patients whose hospital notes were then traced. Notes were reviewed by SEO and CSR and data on patients' treatment and survival were recorded on a standard form.

In 31 patients the hospital notes had been lost and information was not therefore available for these. Some 112 patients were excluded from analysis because they had been referred from outside the Nottingham-served catchment population (population 725000). A further 85 patients were excluded as they had a nonoesophageal primary tumour (55) or were diagnosed before 1982 (30). This left 268 patients, who form the basis of the study. Particular care was taken to exclude patients with endoscopic, radiological, or surgical evidence of a primary gastric tumour. Patients with postcricoid oesophageal carcinomas have also been excluded.

When patients were lost to hospital follow up, general practice and National Health Service Central Registry records were consulted for current vital status. Chi square statistics were applied to cross-tabulations and the MannWhitney U test was used to test differences between age distributions because of the appreciable skew towards the elderly. Life tables were drawn up by the Kaplan Meier method, and differences between survival evaluated by the logrank test. ${ }^{3}$

\section{Results}

Of the 268 patients with oesophageal cancer (171 men) available for analysis, $131(49 \%)$ cancers were of squamous cell type, $95(36 \%)$ were adenocarcinomas, $19(7 \%)$ were anaplastic, and the remaining $23(6 \%)$ were of unknown histology.

When considered on an 'intention to treat' basis, the major active treatment attempted for patients with squamous cell cancer was surgical resection (44). Some 32 patients (18 men) received endoscopic intubation alone (intubation group) and 27 (15 men) had radical radiotherapy either alone (six) or combined with endoscopic intubation (21) (radiation group). The remainder of the group received either combinations of palliative treatments including surgical intubation and palliative radiotherapy (20), or received no treatment (eight).

Endoscopic intubation was with the Atkinson tube, inserted by a standard technique. ${ }^{A}$ External 
TABLE I Radiotherapy in patients undergoing medical treatment

\begin{tabular}{lcl}
\hline Patient & $\begin{array}{l}\text { Tumour dose } \\
(c G y)\end{array}$ & Notes \\
\hline $1^{\star}$ & 1656 & Bone metastases identified during treatment \\
$2^{\star}$ & 3000 & Weight 37 kg, condition deteriorating \\
$3^{\star}$ & 3000 & Liver metastases identified during treatment \\
$4^{\star}$ & 3000 & Aged 81 yrs, condition deteriorating \\
$5^{\star}$ & 3000 & Condition deteriorating \\
$6^{\star}$ & 4000 & Lymph node metastases identified \\
7 & 4000 & Surgery planned to follow radiotherapy, responded to this \\
& 4400 & dose alone, survived 5 yrs \\
8 & 4500 & Dondition deteriorating \\
9 & 4500 & Dose restricted due to pneumonconiosis \\
10 & $4500-4999$ & Full dose \\
$11-12$ & $5000-5499$ & Full dose \\
$13-19$ & $>5500$ & Full dose \\
$20-27$ & & \\
\hline
\end{tabular}

^ Radiotherapy course incomplete.

Figure 1: Survival curves for patients with squamous cell oesophageal cancer treated by surgery, radiotherapy (with or without endoscopic intubation), and endoscopic intubation alone.

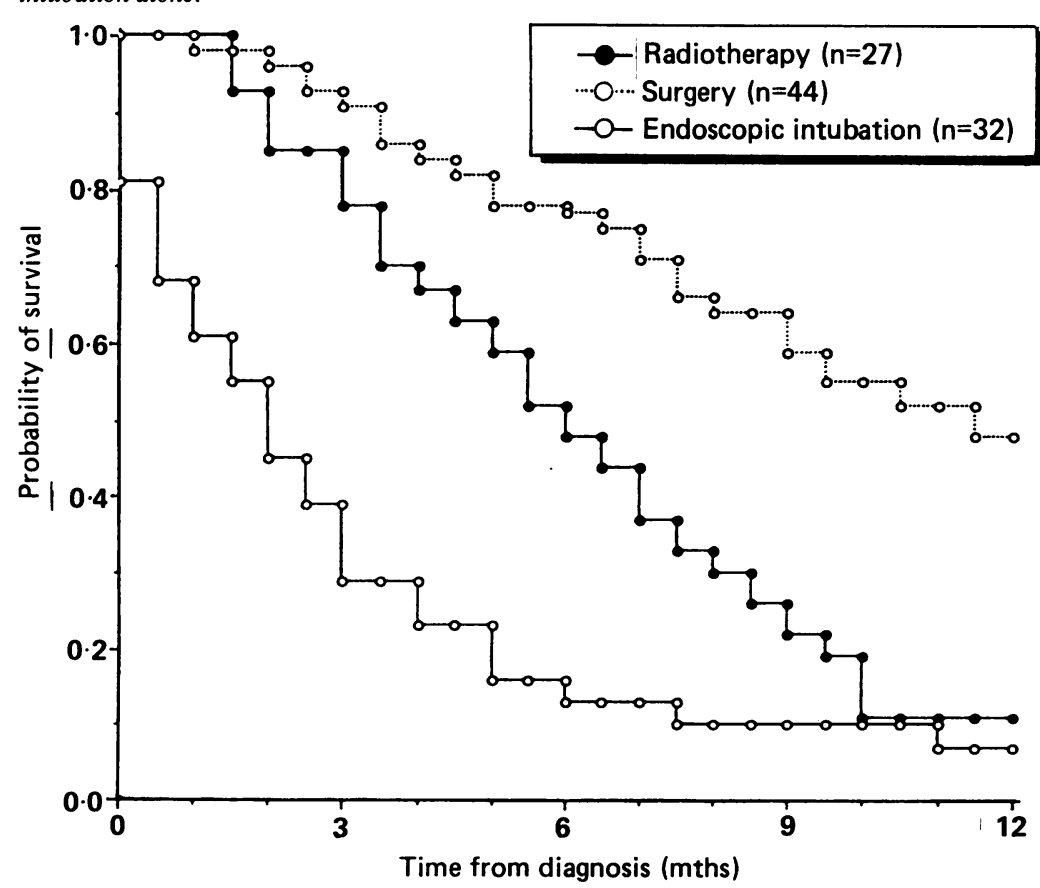
while $11(34 \%)$ in the intubation group died in this period $\left(\chi^{2}=9 \cdot 3, \mathrm{p}<0.005\right)$.

Survival in the radiotherapy group (Fig 1 ) was beam irradiation was delivered using a $6 \mathrm{Mev}$ linear accelerator. A variety of techniques and doses was used depending on whether the treatment intention was radical or palliative. With radical radiation treatment, doses varied from $4500 \mathrm{cGy}$ in 20 fractions to $6000 \mathrm{cGy}$ in 30 fractions. Split course techniques were often used whereby $3000 \mathrm{cGy}$ was given in 15 fractions over three weeks followed by a two week rest period, and then, if the patient's condition allowed, a further 3000 cGy was given. Table I lists the radiotherapy doses received by patients undergoing radical treatment. Seventeen patients had a full course of radical radiotherapy but in the rest the dose was reduced for the reasons given in Table $I$.

Patients who had endoscopic intubation alone had a mean (SD) age of $75(-9)$ years and were significantly older than radiotherapy patients (Mann-Whitney U test, $\mathrm{p}<0.02$ ), who had a mean (SD) age of 69 ( -7 years). Metastases were more often evident in intubation group patients (31\%) than in those receiving radiotherapy $(11 \%)$ $\left(\chi^{2}=2 \cdot 4,0.05<p<0 \cdot 1\right)$. No patient in the radio-

significantly greater than in the group who had intubation alone (logrank $\chi^{2}=7.9, \mathrm{p}<0.005$ ). Median (confidence intervals (CI)) survival in the radiotherapy group was 188 (133-253) days, and the survival rate was $52 \%$ at six months and $11 \%$ at one year. In the intubation group there was a median (CI) survival of 75 (31-98) days and survival rates of $13 \%$ and $7 \%$ at six months and one year respectively (Table II). The surgical group had a median (CI) survival of 364 $(255-465)$ days and survival rates of $98 \%, 80 \%$, and $48 \%$ at 30 days, six months, and one year respectively.

Intubation was often carried out to relieve dysphagia before deciding whether to offer radiotherapy. To receive radiotherapy therefore patients had to survive the early stages of their hospital admission, and, in most cases, recover from an intubation procedure. To make some allowance for this selection effect, survival of the two groups has been compared after excluding all deaths within 30 days of diagnoses (Fig 2). Survival in the radiotherapy group was unchanged, but in the group who had intubation alone, median (CI) survival increased to 98 (73-154) days, with survival rates of $19 \%$ and $10 \%$ at six months and one year respectively. There was no longer a significant difference in overall survival (logrank $\chi^{2}=2 \cdot 5, p>0 \cdot 1$ ). The median (CI) difference in survival rates between the radiotherapy and intubation groups at six months was $33(8-58) \%$, and at one year it was $2(-16-19) \%$. For the 17 patients who completed their radical radiotherapy course, median $(\mathrm{CI})$ survival was 226 (136-278) days and the median (CI) survival of those not completing radical radiotherapy was $119(64-288)$ days. Five patients survived over one year; three had received radiotherapy (surviving 368,389 , and 1830 days) and two had been intubated only (surviving 376 and 737 days).

If patients dying before 30 days are excluded, the median time spent in hospital was 46 days for the radiotherapy group and 23 days for the group receiving intubation alone. Some $67 \%$ of the intubation group spent less than one fifth of their eventual survival in hospital, while this applied to only $44 \%$ of the radiotherapy group.

\section{Discussion}

While most would agree that early oesophageal cancer is best treated by surgical resection, ${ }^{5-7}$ there is no consensus on the best management for oesophageal cancer that is regarded as inoperable because of its extent or the patient's fitness. In selected series good results have been reported with radical radiotherapy..$^{8-10}$ However, hopes that the Medical Research Council trial of radiotherapy and surgery would clarify radiotherapy's role have foundered with the closure of the trial due to poor case recruitment (MRC, personal communication). In patients with advanced disease or whose condition is poor, endoscopic intubation, laser therapy, bipolar thermocoagulation, and intracavity radiotherapy have all been suggested as suitable palliative measures but, as yet, adequate large scale trials are lacking. 11-14

In the absence of randomised trials, retro- 
TABLE II Survival of squamous cell oesophageal cancer patients in relation to treatment attempted

\begin{tabular}{|c|c|c|c|c|c|c|}
\hline \multirow[b]{2}{*}{ Patient group } & & \multicolumn{3}{|c|}{$\%$ Surviving } & \multirow{2}{*}{$\begin{array}{l}\text { Median } \\
\text { survival } \\
\text { (days) }\end{array}$} & \multirow{2}{*}{$\begin{array}{l}\text { Median stay } \\
\text { in hospital } \\
\text { (days) }\end{array}$} \\
\hline & & 30 days & $6 \mathrm{mths}$ & $1 y r$ & & \\
\hline $\begin{array}{l}\text { Intubation only } \\
\text { Radiotherapy } \\
\text { Surgery attempted }\end{array}$ & $\begin{array}{l}(n=32) \\
(n=27) \\
(n=44)\end{array}$ & $\begin{array}{r}66 \\
100 \\
98\end{array}$ & $\begin{array}{l}13 \\
52 \\
80\end{array}$ & $\begin{array}{r}7 \\
11 \\
48\end{array}$ & $\begin{array}{r}75 \\
188 \\
364\end{array}$ & $\begin{array}{l}23 \\
46 \\
-\end{array}$ \\
\hline
\end{tabular}

Figure 2: Survival curves for patients with squamous cell oesophageal cancer treated by radiotherapy (with or without endoscopic intubation) and endoscopic intubation alone. (Deaths within 30 days are excluded.)

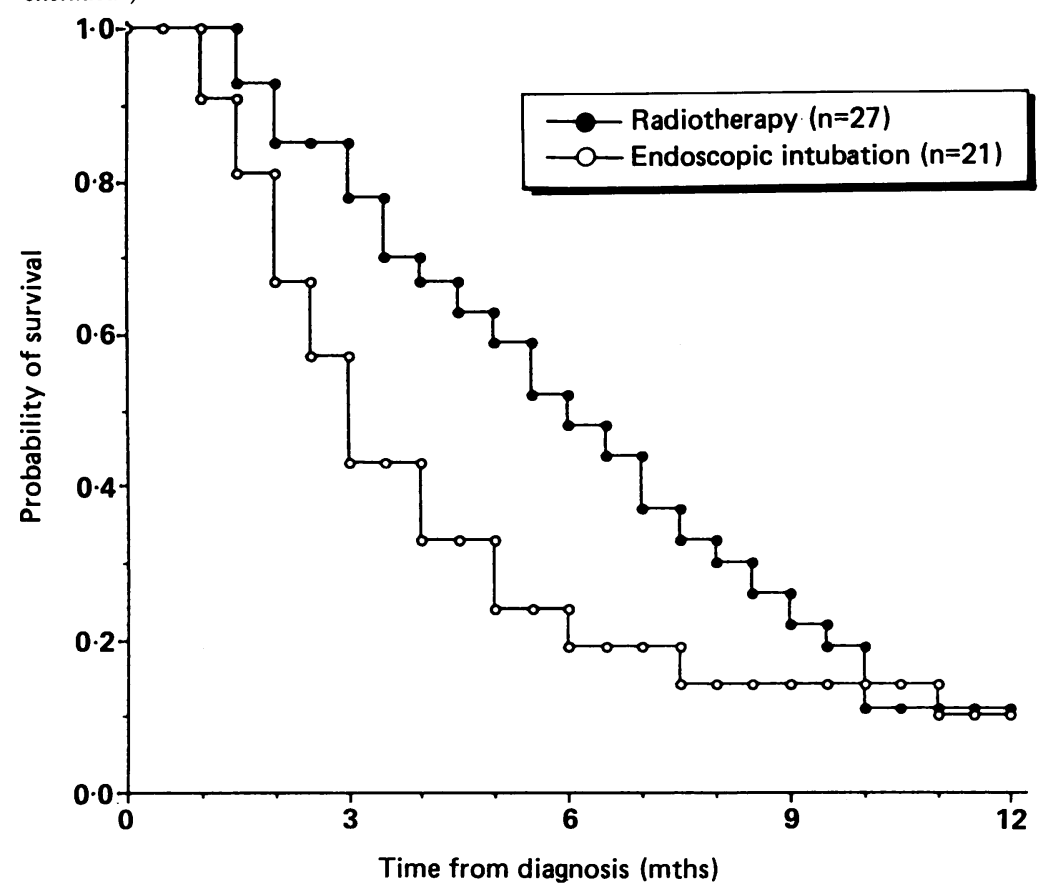

In contrast, survival after radiotherapy in our patients seems disappointing when compared with the one year survivals of $44 \%$ reported by Pearson and of $40 \%$ recently reported from Manchester. ${ }^{810}$ As the authors emphasise, however, the latter figure is based on a highly selected series; only a quarter of the patients referred were given radiotherapy and all were fit enough to complete their course of treatment. Our figure of $11 \%$ survival at one year is nearer the $18 \%$ reported by Earlam and Cunha-Melo in their survey of the reports and the $17 \cdot 5 \%$ survival at one year of 725 patients treated between 1957 and 1981 in the West Midlands. ${ }^{17} 18$

Many patients with inoperable oesophageal cancer are currently treated by endoscopic intubation followed by radiotherapy. Whether, after successful intubation, such a patient should be offered radiotherapy is therefore an important treatment decision. Although overall survival was longer in our patients who had radiotherapy, this difference was not statistically significant and was obtained at the expense of a longer stay in hospital at a time when life expectation is severely limited. The debilitating effects of radiotherapy are also likely to have detracted from the quality of remaining life. Given the considerable selection biases in favour of the radiotherapy group and the small advantage in duration of survival evident, the place of radiation in the management of poor risk patients should be carefully assessed. Our findings show that in patients unsuitable for surgery controlled trials of intubation and radiotherapy are now needed.

1 OPCS. Mortality statistics, cause, 1986. London: HMSO, 1988.

2 Cancer Research Campaign. Trends in cancer survival in Great Britain. London: CRC, 1982.

3 Peto R, Pike MC, Armitage P, et al. Design and analysis of randomised clinical trials requiring prolonged observation of each patient, II, Analysis and examples. Br J Cancer 1977; 35: 1-39.

4 Ogilvie AL, Dronfield MW, Ferguson R, Atkinson M. Palliative intubation of oesophago-gastric neoplasms at fibreoptic endoscopy. Gut 1982; 23: 1060-7.

5 Sugimachi K, Matsuzaki K, Matsuura $\mathrm{H}$, et al. Evaluation of surgical treatment of carcinoma of the oesophagus in the elderly; 20 years experience. Br J Surg 1985; 72: 28-30.

6 McKeown KC. The surgical treatment of carcinoma of the oesophagus. A review of the results in 478 cases. $J R$ Coll Surg Edinb 1985; 30: 1-14.

7 Hennessey TPJ, O'Connell R. Carcinoma of the hypopharynx, esophagus and cardia. Surg Gynecol Obstet pharynx, esophagus

8 Pearson JG. The radiotherapy of carcinoma of the oesophagus and postcricoid region in South-East Scotland. Clin Radiol 1966: 17: 242-57.

9 Newaishy GA, Read GA, Duncan W, Kerr GR. Results of radical radiotherapy in squamous cell carcinoma of the oesophagus. Clin Radiol 1982; 33: 347-52.

10 Slevin NJ, Stout R. Carcinoma of the oesophagus - a review of 108 cases treated by radical radiotherapy. Clin Radio 1989; 40: 200-3.

11 Rowland CG, Pagliero KM. Intracavitary irradiation in palliation of carcinoma of the oesophagus and cardia. Lancet 1985; ii: 981-2.

12 Krasner N, Barr H, Skidmore C, Morris AI. Palliative lase therapy for malignant dysphagia. Gut 1987; 28: 792-8

13 Bown SG, Hawes R, Matthewson K, et al. Endoscopic laser palliation for advanced malignant dysphagia. Gut 1987: 28: palliation

14 Johnston JH, Fleischer D, Petrini J, Juergen Nord H Palliative bipolar electrocoagulation therapy of obstruct ing esophageal cancer. Gastrointest Endosc 1987; 33: 349-53.

15 Hennessey TPJ, O'Connell R. Surgical treatment of squamous cell carcinoma of the oesophagus. Br J Surg 1984: 71: 750-1.

16 Desa L, Raghunath AS, Chawla SL, Peel ALG, Dellipiani AW. Treatment policy for the management of carcinom of the oesophagus. BrJ Surg 1988; 75: 275-8.

17 Earlam RJ, Cunha-Melo JR. Oesophageal squamous cell carcinoma: A critical review of radiotherapy. Br J Surg 1980;67: 457-61.

18 Matthews HR, Waterhouse JAH, Powell J, McConkey CC Robertson JE, eds. Clinical cancer monographs Vol 1 . Cancer of the oesophagus. Basingstoke: MacMillan, 1987. 